\title{
Problems of improving pedagogical skills of future teachers of mathematics
}

\author{
Sergey Yekimov ${ }^{1, *}$, M.V. Klimenko², T.A. Stepchenko², Diliara Iakovets $^{3}$, and Galina \\ Zelenova $^{4}$ \\ ${ }^{1}$ Publishing House "Education and Science", Olstynska 607/1, Praha 8, 18100 Czech Republic \\ ${ }^{2}$ Bryansk State University named after academician I.G. Petrovsky, Bryansk, Russia \\ ${ }^{3}$ Astrakhan State University, Astrakhan, Russia \\ ${ }^{4}$ Don State Technical University, Volgodonsk, Rostov region, Russia
}

\begin{abstract}
The modern education system is facing new requirements and the society is putting forward new requirements among which the leading role is to improve the professional competence of teachers of mathematical disciplines. Mathematics has been used since the time of Pythagoras as the main tool for solving various practical problems in many areas of human activity. In this regard, there is a need to improve the level of mathematical training of modern youth. We believe that the training of future teachers of mathematical disciplines should be based on the principle of integration of humanitarian and mathematical skills, as well as wider use of information technology. In our opinion, such multi-faceted training will help future mathematics teachers to develop the skills required to form a correct understanding of the essence of mathematics, its significance for other Sciences and its significance for everyday life.
\end{abstract}

\section{Introduction}

Recently, the school system has undergone significant changes. Modern life dictates the need to change the paradigm in educational activities, in the direction of humanistic traditions and cultural human values. The priority direction of development of school education is the formation of conditions for individual improvement for all students. This, in turn, leads to an increase in the differentiated approach to education, the interaction of educational institutions at various levels is expanding, and a system of continuous learning is being formed.

These trends in evolutionary development make new demands on the formation of professional pedagogical skills, the defining direction is to promote the full development of the student as a person. There is a turn of the educational system to the person, to his aspirations and problems, new needs of society cause the development of personalityoriented education in the direction of reducing the template approach and averaging .

The scale of changes taking place in the modern world encourages teachers to implement humanistic approaches in educational activities.

${ }^{*}$ Corresponding author: https://orcid.org/0000-0001-6575-2623 
The main goal of the teacher is to determine the innate characteristics and predispositions of each student and provide comprehensive assistance in the development of their abilities, inclinations and interests. In our opinion, the main school educational programs should be focused on promoting the formation of a common culture and creating conditions for students to make an informed choice of their future profession. At the same time, the dynamics of the development of modern society and the processes of globalization in the modern world place increased demands on the level of mathematical education.

In our opinion, the effective socio-political and economic development of modern education depends to a large extent on the quality of mathematical education.

According to Kovtonyuk M. M., \& V., Didovyk. (2018), Urazbaeva, Manzura. (2013) natural science and mathematics education have recently become important elements in the training of most specialists in the Humanities.

According To Faria, Paulo \& Moro, Maria \& Brito, Marcia. (2008), Zhernovnykova, Oksana. (2016), HODOVANIUK, Tetiana. (2019) the most important task of teaching mathematics at school is to develop thinking skills that are of great importance in everyday human activities.

According to Polischuk, Tetana \& Ischenko, Galyna \& Voznosymenko Daria. (2020) pedagogical skills provide for the teacher to have a high responsibility to society for teaching the younger generation the ability to optimally use various pedagogical techniques in their professional activities.

According to Karakasheva, L.. (2018), Bakhytkul, Kaskatayeva \& Asilkhanovna, BATYRBAEVA. (2020) pedagogical skills is an indicator characterizing the use of various professional skills of teachers, it provides the presence of of innovative approaches in the performance of their professional duties, a thorough knowledge of subjects, fluency in various methods of teaching, availability of learning, aesthetic and cultural horizons, the possession of managerial skills, psychological preparation and culture of speech.

According to Akhmetzyanova, Guliya \& Bagateeva, Angelina \& Sirazov, Fannur. (2019) the presence of pedagogical skills implies that a teacher teaching mathematical subjects has logical thinking skills, an understanding of various mathematical models and the ability to link them to real life processes, a predisposition to intellectual work and the ability to set and solve new mathematical problems.

Authors Rozumenko, A. O. \& Rozumenko, A. M.. (2020), Popov, Nikolai \& Kalimova, Anna. (2019) note the ability to accept and understand the reasoning of students, the ability to work together with students to analyze their mistakes among the important conditions for having pedagogical skills.

In Dyupina, Anastasiya \& Falileeva, Marina. (2020), the teacher's possession of variable thinking skills can also be an attribute of pedagogical skill.

According to Troitskaya, O. \& Vohtomina, E.. (2019), pedagogical skills should provide for the presence of inter-subject connections in the teacher, he should be able to cooperate with colleagues teaching computer science, physics and other academic disciplines.

According to Simonovskaya, G. A.. (2020) the presence of pedagogical skills should provide for the presence of the teacher's personal style of his professional activity.

The authors Semenikhina, Olena \& Proshkin, Volodymyr. (2018) note that the possession of pedagogical techniques that can increase the effectiveness of the tools , methods and principles of teaching and upbringing is an integral component of pedagogical skill.

According to Kushniruk, A.. (2019) pedagogical skill of a mathematics teacher implies the ability to apply a variety of logical methods in their professional activities : induction , deduction, generalization, analogy, synthesis, comparison, analysis . It is also important to know the logical laws and methodology of logical thinking. 
According to Shashkina, Mariya \& Ayoshina, Ekaterina. (2015) pedagogical skills of a mathematics teacher should include the ability to use forms and methods of dialectical, formal and mathematical logic, and have the skills of meaningful logical speech .

\section{Methods}

In carrying out this research, we used an analytical method by which the problems we studied found their consideration in their unity and development.

Taking into account the goals and objectives of this study, a functional and structural method of implementing scientific research was used.

This allowed us to consider some of the problems associated with the training of math teachers.

\section{Results}

We believe that the ability to use computer technologies in teaching mathematics is currently an important component of pedagogical skills, which increases the teaching of mathematics to a qualitatively new level.

Need application in the study of mathematics is caused by the features : visualization of information on objects and objects, the presence of fast communication between computers and users, automation of calculations, searching and processing information-methodical information, an ability to control the absorption of educational material.

We believe that computer technologies can play an important role in improving the competencies associated with the ability to:

1. Acquire new knowledge using modern information and educational technologies;

2. Use numerical and analytical technologies for solving problems using computer technology;

3. Work as a team and solve problems on your own;

4. persevere in achieving your goals;

5. Develop research skills.

At the same time, we believe that a math teacher should also have a pedagogical culture, which means that the teacher has:

1. The ability to understand the characteristics of the General and psychological development of each student;

2. The ability to diagnose, analyze, evaluate and plan the educational process;

3. The ability to develop new methods and forms of teaching mathematical subjects;

4. Systems of ethical and moral values, which include a set of skills related to the relationship between society and the individual, the desire to work in school ;

The process of forming a future teacher's pedagogical culture, in our opinion, is associated with the integration of professional socialization and improvement of professional skills in the educational process. In addition, in our opinion, it is very important for the education of future teachers :

1. Motivations for personal perception of professional and humanistic motivations;

2. Striving for theoretical and practical professional training;

3. The ability to use inter-subject relationships when teaching mathematics;

4. Professional socialization.

This will allow, in our opinion:

1. Combine the humanitarian and technological literacy of future teachers;

2. Will have a positive impact on the formation and improvement of professional skills of the future mathematics teacher; 
3. Will allow the future teacher to improve the skills of using traditional and informational pedagogical technologies.

\section{Discussion}

In mathematics, the world around us is represented by judgments, concepts, conclusions, scientific ideas and theories. Mathematical concepts are usually purely theoretical in nature. Their practical application occurs by moving to the concrete from the abstract. The invariant basis of mathematical knowledge includes theoretical and explanatory components.

For successful teaching of mathematics, in our opinion, it is necessary to use the pedagogical and psychological disciplines of information technology.

We believe that the training of future teachers of mathematical disciplines should be based on the principle of integration of humanities and mathematical skills.

Such comprehensive training, in our opinion, will contribute to the emergence of future teachers of mathematics skills necessary for the formation of students ' correct understanding of the essence of mathematics, its significance for other sciences and its significance for everyday life.

\section{Conclusions}

In modern times, new requirements are imposed on the education system, among which the primary importance is to improve the professional competence of teachers. Mathematics is used as the main tool for solving various practical problems in many areas of human activity. In this regard, there is a need to improve the level of mathematical training of modern youth.

Pedagogical higher education institutions provide graduates with a wide range of skills, knowledge and skills. However, there is a need for continuous improvement of teachers ' knowledge due to the fact that life stands still. At the same time, mathematics, in our opinion, is an important element of culture for modern people, as well as a highly effective way to solve various practical problems.

\section{References}

1. Guliya Akhmetzyanova, Angelina Bagateeva, Fannur \& Sirazov, Journal of Computational and Theoretical Nanoscience, 16, 4550 (2019)

2. Kaskatayeva Bakhytkul, Asilkhanovna Bakhytkul, International Journal of Engineering Technologies and Management Research, 4, 13 (2020)

3. Anastasiya Dyupina, Marina Falileeva, Russian Digital Libraries Journal, 23, 49 (2020)

4. Paulo Faria, Maria Moro, Marcia Brito, Estudos de Psicologia (Natal), 13, 257 (2008)

5. Tetiana Hodovaniuk, Cherkasy University Bulletin: Pedagogical Sciences, 2, 141 (2019)

6. L. Karakasheva, Some Ideas for Applying the Synergetic Approach in Training Future Teachers of Mathematics, Science and Education a New Dimension, VI(30), 51 (2018)

7. M.M. Kovtonyuk, V. Didovyk, Modern Information Technologies and Innovation Methodologies of Education in Professional Training Methodology Theory Experience Problems, 434, 293 (2018) 
8. A. Kushniruk, Pedagogy of the formation of a creative person in higher and secondary schools, 64, 139 (2019)

9. Tetana Polischuk, Galyna Ischenko, Daria Voznosymenko, Problems of Modern Teacher Training, 111 (2020)

10. Nikolay Popov, Anna Kalimova, Physics and Informatics, 8(1), 12 (2019)

11. A.O. Rozumenko, A.M. Rozumenko, Physical and Mathematical Education (2020)

12. Olena Semenikhina, Volodymyr Proshkin, Application of Computer Mathematical Tools in Professional Preparation of Future Teachers of Mathematics, Open Educational E-Environment of Modern University, 60 (2018)

13. Mariya Shashkina, Ekaterina Ayoshina, The Education and science journal, 9, 51 (2015)

14. G.A. Simonovskaya, Educational Psychology in Polycultural Space, 51, 121 (2020)

15. O. Troitskaya, E. Vohtomina, Informatics and education, 34(8), 24 (2019)

16. Manzura Urazbaeva, Formation of the methodical skills of future teachers of mathematics, GISAP:Physics, Mathematics and Chemistry (2013)

17. Oksana Zhernovnykova, Training Future Teachers of Mathematics: A Historical Perspective, International Letters of Social and Humanistic Sciences, 66, 140 (2016) 